\title{
Precipitation and soil particle size co-determine spatial distribution of biological soil crusts in the Gurbantunggut Desert, China
}

\author{
WU Lin ${ }^{1,2}$, ZHANG Yuanming ${ }^{2 *}$ \\ ${ }^{1}$ Hubei University for Nationalities, Enshi 445000, China; \\ ${ }^{2}$ Key Laboratory of Biogeography and Bioresource in Arid Land, Xinjiang Institute of Ecology and Geography, Chinese \\ Academy of Sciences, Urumqi 830011, China
}

\begin{abstract}
Biological soil crusts (BSCs) are bio-sedimentary associations that play crucial ecological roles in arid and semi-arid regions. In the Gurbantunggut Desert of China, more than $27 \%$ of the land surface is characterized by a predominant cover of lichen-dominated BSCs that contribute to the stability of the desert. However, little is known about the major factors that limit the spatial distribution of BSCs at a macro scale. In this study, the cover of BSCs was investigated along a precipitation gradient from the margins to the center of the Gurbantunggut Desert. Environmental variables including precipitation, soil particle size, soil $\mathrm{pH}$, electrical conductivity, soil organic carbon, total salt, total nitrogen, total phosphorus and total potassium were analyzed at a macro scale to determine their association with differing assemblages of BSCs (cyanobacteria crusts, lichen crusts and moss crusts) using constrained linear ordination redundancy analysis (RDA). A model of BSCs distribution correlated with environmental variables that dominated the first two axes of the RDA was constructed to clearly demonstrate the succession stages of BSCs. The study determined that soil particle size (represented by coarse sand content) and precipitation are the most significant drivers influencing the spatial distribution of BSCs at a macro scale in the Gurbantunggut Desert. The cover of lichen and moss crusts increased with increasing precipitation, while the cover of cyanobacteria crusts decreased with increasing precipitation. The cover of lichen and moss crusts was negatively associated with coarse sand content, whereas the cover of cyanobacteria crusts was positively correlated with coarse sand content. These findings highlight the need for both the availability of soil moisture and a relatively stable of soil matrix, not only for the growth of BSCs but more importantly, for the regeneration and rehabilitation of disturbed BSC communities in arid and semi-arid lands. Thereby, this study will provide a theory basis to effectively increase soil stability in desert regions.
\end{abstract}

Keywords: biological soil crust; distribution; macro scale; redundancy analysis (RDA); disturbance; temperate desert

Citation: WU Lin, ZHANG Yuanming. 2018. Precipitation and soil particle size co-determine spatial distribution of biological soil crusts in the Gurbantunggut Desert, China. Journal of Arid Land, 10(5): 701-711. https://doi.org/10.1007/s40333-018-0065-3

\section{Introduction}

Biological soil crusts (BSCs) are complex matrices of soil particles, cyanobacteria, algae, lichens, mosses, liverworts and microfungi (Belnap, 2001). In undisturbed areas, BSCs can completely

\footnotetext{
*Corresponding author: ZHANG Yuanming (E-mail: zhangym@ms.xjb.ac.cn)

Received 2017-10-16; revised 2018-01-11; accepted 2018-02-03

C Xinjiang Institute of Ecology and Geography, Chinese Academy of Sciences, Science Press and Springer-Verlag GmbH Germany, part of Springer Nature 2018
} 
cover interplant surfaces and thus constitute as much as $70 \%$ of living cover in arid areas (Belnap, 2003). Despite their unassuming appearance, the diminutive organisms that comprise BSCs, surprisingly play many important ecological roles in arid lands. BSCs are known to increase soil stability (Eldridge, 1998; Eldridge and Leys, 2003) and nutrient availability (Bowker, 2007), to influence soil hydrological cycles in arid lands (Belnap, 2006; Garibotti et al., 2018), to improve seedling establishment of grasses and shrubs (Deines et al., 2007; Peter et al., 2016), and to provide habitats and food sources for reptiles and invertebrates (Lalley et al., 2006a; Li et al., 2011). Crust function is tied to crust community types (Pietrasiak et al., 2013) and surface morphology, and these variables vary greatly between climatic regions (West, 1990).

Many studies have examined the relationships between environmental variables and crust composition and cover to determine which variables have the greatest impact on crust development. In the absence of disturbance, many biotic and abiotic factors have been found to contribute both to distribution patterns of BSCs and to differences in species composition. These factors include precipitation (Belnap et al., 2007; Büdel et al., 2009), geomorphology (Kidron et al., 2010; Pietrasiak et al., 2011; Williams et al., 2013; Bu et al., 2016), soil texture (Lalley et al., 2006a), soil pH (Rivera-Aguilar et al., 2009), dust deposition (Kidron et al., 2000; Lalley et al., 2006b), vascular plants (Bowker, 2007; Li et al., 2010), and UV-B radiation (Castenholz and Garcia-Pichel, 2000). Most of these studies were concentrated on either hot or cold deserts, such as the Colorado Plateau (Pietrasiak et al., 2011), Great Basin Desert (Belnap and Lange, 2003), Mojave Desert (Williams et al., 2013), Negev Desert (Kidron et al., 2010), Namib Desert (Büdel et al., 2009), Kalahari Desert (Thomas and Dougill, 2007), deserts in Australia (Eldridge, 2003; Rogers, 2006) and Zapotitlán drylands (Rivera-Aguilar et al., 2009), but little is known in drier, temperate deserts, such as the Gurbantunggut Desert, where BSCs are patchy in distribution.

The Gurbantunggut Desert of China is remote from the sea and is surrounded by high mountains. It is a typical temperate desert with a climate permanently in drought. Lichen-dominated BSCs are abundant in the Gurbantunggut Desert. Zhang et al. (2004) described the characteristics of BSCs distribution on sand dunes in this desert and found that the species composition varied with different successional stages of BSCs. Chen et al. (2007) suggested that, at the sand dune scale, both thickness and cover of BSCs are linked to soil physical-chemical properties and topsoil textural stability. At a regional scale, lichen and moss crusts are found mainly in the southern region of the Gurbantunggut Desert. Crust cover becomes sparse to the northern part and is absent in the eastern and western parts of the desert (Zhang et al., 2007). However, it is not clear how abiotic factors influencing species composition and BSCs distribution in this temperate desert.

In recent years, BSCs in the Gurbantunggut Desert have undergone significant disturbance as a result of intensive human activities, particularly grazing, and road building and construction. Locations that have experienced frequent disturbance are characterized by extensive areas of loose sand and are largely devoid of vegetation (Wang et al., 2006). BSCs are completely destroyed by bulldozers for the use of road building and the construction of oil production infrastructure, and the ensuing crust removal is followed by significant changes in the structure of the soil surface. Although disturbance intensity appears to be the primary predictor of crust development, some relatively undisturbed areas cannot develop crusts. Therefore, a macro-scale study can help to explain the mechanism of the formation and distribution patterns of BSCs. This data can be utilized to improve strategies for conservation of existing BSCs resources, and provide effective suggestions for soil rehabilitation and regeneration of BSCs in disturbed areas.

Our primary goal for this study was to understand the factors driving the distribution and abundance of BSCs in the Gurbantunggut Desert. Specifically, our objective was to assess the distribution and abundance of BSCs throughout the Gurbantunggut Desert by studying the relationship between biotic and abiotic factors with the development and distribution of crusts. In the Gurbantunggut Desert, mean annual precipitation decreases significantly from the outer edge inward to the center of the desert and this is accompanied by increased evaporation from the boundary to the center of the Jungger Basin in which the desert is located. Frequent sandstorms lead to a spatial variation in soil grain size at a macro scale, which significantly affects the spatial 
differentiation of vascular plants (Qian et al., 2009). Therefore, we hypothesized that precipitation and soil grain size would be the major limiting factors for determining the spatial distribution of BSCs at a macro scale.

\section{Materials and methods}

\subsection{Study area}

The study was carried out in the Gurbantunggut Desert $\left(44^{\circ} 11^{\prime}-46^{\circ} 20^{\prime} \mathrm{N}, 84^{\circ} 31^{\prime}-90^{\circ} 00^{\prime} \mathrm{E}\right.$; Fig. 1) located in the Jungger Basin, Xinjiang, China. This desert is the largest fixed and semi-fixed desert in China with an area of $4.88 \times 10^{4} \mathrm{~km}^{2}$. The desert landscape is dominated by a mix of longitudinal, crescent-shaped and honeycomb sand dunes. Elevation ranges from 312 to $743 \mathrm{~m}$ a.s.1. The desert is characterized by an arid climate. Mean annual precipitation varies from 70 to $160 \mathrm{~mm}$, falling predominantly in spring. Mean annual potential evaporation is $2607 \mathrm{~mm}$. Annual mean temperature is $6^{\circ} \mathrm{C}-10^{\circ} \mathrm{C}$ and the maximum summer temperature can exceed $40^{\circ} \mathrm{C}$. Wind speeds are highest in late spring, with an average of $11.17 \mathrm{~m} / \mathrm{s}$. The prevailing wind comes from the WNW, NW and N directions. The soil stability of the Gurbantunggut Desert is dependent on native vascular plant vegetation and well-developed surface cover of BSCs (Chen et al., 2007).

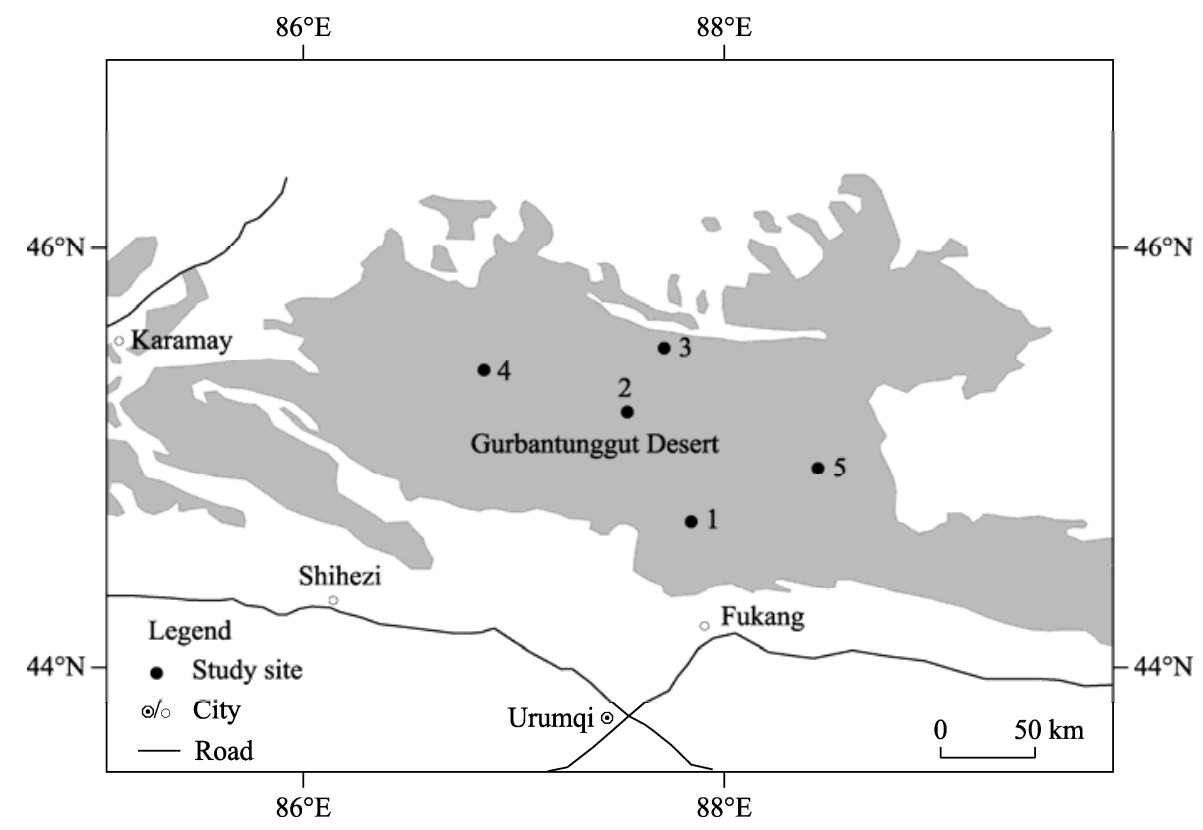

Fig. 1 Locations of the five study sites in the Gurbantunggut Desert. Note: each site comprises 120 quadrats.

\subsection{Experimental design}

The field investigation was started in October 2012. In autumn, BSCs are conspicuous and readily identified because most vascular plants (shrubs, subshrubs and perennial herbs) have either disappeared or returned to low levels of physiological activity. Five study sites (Fig. 1) representing five desert regions were selected to evaluate the spatial distribution of BSCs in different regions of the desert, and to determine the environmental variables affecting the distribution of BSCs at a macro scale. A nested sampling design was used, i.e., six $10 \mathrm{~m} \times 20 \mathrm{~m}$ plots with well-developed BSCs and spaced $500 \mathrm{~m}$ apart were established in each of the five sites. It should be noted that these plots were distributed between sand dunes to eliminate the interference of spatial heterogeneity. Within each plot, four $5 \mathrm{~m} \times 5 \mathrm{~m}$ subplots were placed in the interdune without causing any disturbances. In each subplot, five $50 \mathrm{~cm} \times 50 \mathrm{~cm}$ quadrats $(2.5$ $\mathrm{cm} \times 2.5 \mathrm{~cm}$ grid; 400 points per quadrat) positioned at $3 \mathrm{~m}$ intervals were selected to determine the cover of BSCs, giving a total of 120 quadrats at each site ( 6 plots $\times 4$ subplots $\times 5$ quadrats). 
Prior to taking measurements, the soil surface was sprayed with water to make the BSC components more readily visible. BSC cover was estimated as the proportion of the 400 points per quadrat occupied by the visible components on the crusts (lichen, moss and cyanobacteria), as described by Li et al. (2010). The cover of BSCs was then categorized as lichen crust cover, moss crust cover and cyanobacteria crust cover. Cyanobacteria often occur in the earliest successional stages of BSCs, followed by lichen, and finally, moss (Bowker, 2007). Moreover, in order to discuss the influence of environmental variables on the succession of BSCs, we defined four dominant BSC types by their relative cover: cyanobacteria crusts, cyanobacteria and lichen crusts (cyanobacteria dominant with lichen present), lichen and cyanobacteria crusts (lichen dominant with cyanobacteria present), and lichen and moss crusts (both lichen and moss present).

\subsection{Soil sampling and analysis}

Three soil samples were collected from a depth of $0-10 \mathrm{~cm}$ in each subplot and then taken back to the laboratory where each soil sample was air-dried, crushed and passed through a 2-mm sieve. Soil $\mathrm{pH}$ was determined in a 1:5 soil:water suspension by a calibrated $\mathrm{pH}$ meter (PHS-4, Jiangsu Manufactory of Electrical Analysis Instruments, Jiangyin, China). Electrical conductivity (EC) was measured by DDS-11A. Soil organic carbon (SOC) was analyzed by the $\mathrm{K}_{2} \mathrm{Cr}_{2} \mathrm{O}_{7}$ method (GB9834-88); total nitrogen by the $\mathrm{CuSO}_{4}$-Se powder diffusion method (GB7848-87); total phosphorus by the $\mathrm{NaOH}$ Melting-Mo Te Sc Colorimetry method (GB7852-87); and total potassium by the $\mathrm{NaOH}$ Melting-Flaming luminosity method (GB7854-87). Total salt was measured using methods described by the Nanjing Institute of Soil Research, Chinese Academy of Sciences (1980). All these parameters were selected for their potential to explain the distribution of BSCs (Bowker et al., 2006; Li et al., 2011). Soil particle size was determined using standard dry-sieving techniques. Resultant material was then allocated into four categories: coarse sand $(0.500-2.000 \mathrm{~mm})$, sand $(0.250-0.500 \mathrm{~mm})$, fine sand $(0.0625-0.250 \mathrm{~mm})$, and silt $(<0.0625$ $\mathrm{mm})$. Levels of calcium carbonate $\left(\mathrm{CaCO}_{3}\right)$ were determined by titration (Morse et al., 2007).

\subsection{Climate data collection}

Precipitation data from 2005 to 2011 were obtained for the five study sites. Precipitation data for site 1 was from the Fukang National Field Scientific Observation and Research Station for Desert Ecosystems $\left(44^{\circ} 17^{\prime} \mathrm{N}, 87^{\circ} 56^{\prime} \mathrm{E} ; 475 \mathrm{~m}\right.$ a.s.1.). Data for sites 2 and 3 were obtained from the field meteorological stations (Watchdog1000, SPECTRUM, USA), and data for sites 4 and 5 were collected from the meteorological stations of Xinjiang Petroleum Administrative Bureau. At each meteorological station, the hourly precipitation was obtained though disaggregation of daily observation measured using a standard rain gauge designed by the Chinese Government.

\subsection{Data analysis}

In this study, the differences in BSC variables and soil parameters among different plot locations at a macro scale were analyzed using one-way analysis of variance (ANOVA) at the $95 \%$ significance level. Data analysis was carried out with SPSS version 16.0 software (Chicago, IL, USA). The least significant difference (LSD) multiple comparison test was used to determine differences among soil parameters and BSC cover values. The data are presented as mean $\pm \mathrm{SE}$. The map of the Gurbantunggut Desert was made by ArcGIS 10.0. The redundancy analysis (RDA) bi-plot was created with CANOCO 4.5 and the other figures were created with Origin 8.0 software (OriginLab, USA).

CANOCO is one of the most popular programs for multivariate statistical analysis using ordination methods in the field of ecology and several related fields (ter Braak, 1988). Constrained linear ordination technique RDA was used in CANOCO 4.5 to analyze the influence of environmental variables on the cover of BSCs. RDA is a direct gradient analysis or constrained ordination method, where the differences in cover measures (response variables) across the plots are explained by ordination axes of the environmental variables (Kindt and Coe, 2005). Coarse sand $(0.500-2.000)$ and silt $(<0.0625 \mathrm{~mm})$ were chosen to represent the distribution of soil particle sizes, as they showed the lowest correlation with one another (Lalley et al., 2006a). Soil $\mathrm{EC}$ and $\mathrm{pH}$ were measured simultaneously in the same leach liquor and their values are thus 
interrelated. Soil $\mathrm{pH}$ was significantly correlated with the cover of BSCs in arid environments (Lalley et al., 2006a; Li et al., 2010), and then it was chosen to represent the group (environmental variables) in our study. It should be noted that in this study, the reduced number of environmental variables and the cover of BSCs were standardized before being entered into the RDA.

\section{Results}

\subsection{Spatial heterogeneity on the distribution of BSCs}

In the Gurbantunggut Desert, there were significant differences not only in the dominant types of BSCs but also in the percentage cover at a macro scale. The highest total cover of BSCs occurred in the southern site of the desert where moss and lichen crusts covered almost the entire soil surface (Table 1). BSCs were slightly less abundant in the central site of the desert and sparsest in the eastern site where the covers of cyanobacteria and lichen crusts were $23.83 \%$ and $1.54 \%$, respectively. In the western site, the interdune surface was covered by $2.16 \%$ moss crusts, $28.72 \%$ cyanobacteria crusts and $59.99 \%$ lichen crusts. In contrast, in the northern site, the covers of cyanobacteria crusts, lichen crusts and moss crusts were $55.32 \%, 24.48 \%$ and $1.02 \%$, respectively.

Table 1 Spatial characteristics of biological soil crusts (BSCs) in the five study sites

\begin{tabular}{cccccc}
\hline Site & $\begin{array}{c}\text { Total cover } \\
(\%)\end{array}$ & $\begin{array}{c}\text { Moss crust } \\
\text { cover }(\%)\end{array}$ & $\begin{array}{c}\text { Lichen crust } \\
\text { cover }(\%)\end{array}$ & $\begin{array}{c}\text { Cyanobacteria } \\
\text { crust cover }(\%)\end{array}$ & Dominant types of BSCs \\
\hline 1 & $94.10 \pm 3.17^{\mathrm{a}}$ & $18.12 \pm 1.89^{\mathrm{a}}$ & $73.18 \pm 2.88^{\mathrm{a}}$ & $3.00 \pm 0.26^{\mathrm{d}}$ & Lichen crusts, moss crusts \\
2 & $89.17 \pm 3.46^{\mathrm{a}}$ & $11.75 \pm 1.62^{\mathrm{b}}$ & $65.43 \pm 2.04^{\mathrm{ab}}$ & $8.75 \pm 1.25^{\mathrm{c}}$ & Lichen crusts, moss crusts \\
3 & $80.82 \pm 3.38^{\mathrm{b}}$ & $1.02 \pm 0.08^{\mathrm{d}}$ & $24.48 \pm 1.06^{\mathrm{c}}$ & $55.32 \pm 2.06^{\mathrm{a}}$ & Cyanobacteria crusts, lichen crusts \\
4 & $83.83 \pm 3.55^{\mathrm{b}}$ & $2.16 \pm 0.13^{\mathrm{c}}$ & $59.99 \pm 1.21^{\mathrm{b}}$ & $28.72 \pm 1.42^{\mathrm{b}}$ & Lichen crusts, cyanobacteria crusts \\
5 & $25.17 \pm 1.79^{\mathrm{c}}$ & $0.00 \pm 0.00^{\mathrm{e}}$ & $1.54 \pm 0.26^{\mathrm{d}}$ & $23.83 \pm 1.65^{\mathrm{b}}$ & Cyanobacteria crusts \\
\hline
\end{tabular}

Note: Sites 1, 2, 3, 4 and 5 are the southern, central, northern, western and eastern sites of the Gurbantunggut Desert, respectively. The total cover of BSCs was calculated as the sum of moss crust cover, lichen crust cover and cyanobacteria crust cover. Different lowercase letters in the same column indicate significance among study sites at $P<0.05$ level. Mean \pm SE.

\subsection{Variation of environmental variables}

Environmental variables (precipitation and soil parameters) differed among the five study sites at a macro scale (Table 2). Precipitation generally decreased from the margins to the center of the desert (Table 2). The highest mean annual precipitation was recorded in the southern site (133.96 $\mathrm{mm})$, followed by the western site $(109.50 \mathrm{~mm})$ and the northern site $(90.27 \mathrm{~mm})$. Moreover, precipitation was lower in the central $(76.26 \mathrm{~mm})$ and eastern $(80.02 \mathrm{~mm})$ sites.

The spatial variations of soil parameters were not consistent with that of precipitation (Table 2). Soil particle size decreased from the northern site to the southern site, and from both the western and eastern sites to the central site. The results are consistent with wind directions in the desert. Soil $\mathrm{pH}$ level and total salt content were highest in the western site, decreased towards the central and northern sites, and were lowest in the eastern site. With the exception of the eastern site, there were no significant differences in $\mathrm{EC}$, total nitrogen, $\mathrm{SOC}$ and $\mathrm{CaCO}_{3}$ among the different study sites. The highest level of total phosphorus was recorded in the southern site. Moreover, significant differences in total potassium were found among the five study sites $(P<0.01)$, with the highest value recorded in the central site and the lowest in the eastern site.

\subsection{Relationship between BSCs cover and environmental variables}

The RDA ordination bi-plot of BSCs cover and environmental variables is shown in Figure 2. Arrows represent correlations of environmental variables with BSCs cover. The first axis of the RDA (eigenvalue $=0.56$ ) explained $56.0 \%$ of the total variation in the cover of BSCs and $79.7 \%$ of the relationship between BSCs cover and environmental variables. Soil particle size distribution was the most significant environmental variable on Axis 1, represented by coarse sand content (canonical coefficient $=0.83$ ). The second most influential environmental variable on both Axis 1 
Table 2 Characteristics of environmental variables (precipitation and soil parameters) in the five study sites

\begin{tabular}{|c|c|c|c|c|c|c|}
\hline Site & $\begin{array}{l}\text { Precipitation } \\
(\mathrm{mm})\end{array}$ & $\begin{array}{c}\text { Coarse sand } \\
(\%)\end{array}$ & $\begin{array}{l}\text { Silt } \\
(\%)\end{array}$ & Soil pH & $\begin{array}{c}\mathrm{EC} \\
(\mathrm{mS} / \mathrm{cm})\end{array}$ & $\begin{array}{l}\text { Total salt } \\
(\mathrm{g} / \mathrm{kg})\end{array}$ \\
\hline 1 & $133.96 \pm 14.20^{\mathrm{a}}$ & $10.43 \pm 2.83^{d}$ & $12.44 \pm 2.48^{b}$ & $7.99 \pm 0.10^{\mathrm{c}}$ & $0.09 \pm 0.01^{\mathrm{a}}$ & $0.39 \pm 0.02^{\mathrm{ab}}$ \\
\hline 2 & $76.26 \pm 12.37^{\mathrm{d}}$ & $12.33 \pm 3.16^{\mathrm{d}}$ & $14.27 \pm 3.37^{\mathrm{b}}$ & $8.28 \pm 0.09^{b}$ & $0.08 \pm 0.01^{\mathrm{a}}$ & $0.38 \pm 0.01^{\mathrm{b}}$ \\
\hline 3 & $90.27 \pm 12.46^{\mathrm{c}}$ & $20.18 \pm 3.54^{\mathrm{b}}$ & $20.36 \pm 3.63^{\mathrm{a}}$ & $8.27 \pm 0.09^{b}$ & $0.08 \pm 0.01^{\mathrm{a}}$ & $0.38 \pm 0.02^{b}$ \\
\hline 4 & $109.50 \pm 13.45^{\mathrm{b}}$ & $15.78 \pm 1.47^{\mathrm{c}}$ & $14.77 \pm 5.85^{\mathrm{b}}$ & $8.43 \pm 0.05^{\mathrm{a}}$ & $0.09 \pm 0.01^{\mathrm{a}}$ & $0.41 \pm 0.03^{\mathrm{a}}$ \\
\hline 5 & $80.02 \pm 11.46^{\mathrm{cd}}$ & $26.39 \pm 2.35^{\mathrm{a}}$ & $2.85 \pm 0.43^{\mathrm{c}}$ & $7.90 \pm 0.20^{\mathrm{c}}$ & $0.07 \pm 0.01^{\mathrm{b}}$ & $0.30 \pm 0.01^{\mathrm{c}}$ \\
\hline Site & $\begin{array}{c}\text { Total nitrogen } \\
(\mathrm{g} / \mathrm{kg})\end{array}$ & $\begin{array}{c}\text { Total phosphorus } \\
(\mathrm{g} / \mathrm{kg})\end{array}$ & $\begin{array}{c}\text { Total potassium } \\
(\mathrm{g} / \mathrm{kg})\end{array}$ & $\begin{array}{c}\mathrm{SOC} \\
(\mathrm{g} / \mathrm{kg})\end{array}$ & $\begin{array}{c}\mathrm{CaCO}_{3} \\
(\mathrm{~g} / \mathrm{kg})\end{array}$ & \\
\hline 1 & $0.21 \pm 0.08^{\mathrm{a}}$ & $0.34 \pm 0.04^{\mathrm{a}}$ & $13.65 \pm 0.11^{\mathrm{d}}$ & $1.55 \pm 0.59^{\mathrm{a}}$ & $12.48 \pm 1.01^{\mathrm{ab}}$ & \\
\hline 2 & $0.14 \pm 0.04^{\mathrm{a}}$ & $0.21 \pm 0.03^{\mathrm{c}}$ & $16.55 \pm 0.13^{\mathrm{a}}$ & $1.21 \pm 0.29^{\mathrm{a}}$ & $12.93 \pm 0.28^{\mathrm{a}}$ & \\
\hline 3 & $0.16 \pm 0.04^{\mathrm{a}}$ & $0.20 \pm 0.05^{\mathrm{c}}$ & $15.60 \pm 0.32^{\mathrm{c}}$ & $1.33 \pm 0.30^{\mathrm{a}}$ & $12.94 \pm 0.56^{\mathrm{a}}$ & \\
\hline 4 & $0.17 \pm 0.07^{\mathrm{a}}$ & $0.23 \pm 0.04^{\mathrm{bc}}$ & $16.28 \pm 0.17^{b}$ & $1.26 \pm 0.57^{\mathrm{a}}$ & $12.97 \pm 0.59^{\mathrm{a}}$ & \\
\hline 5 & $0.06 \pm 0.02^{\mathrm{b}}$ & $0.27 \pm 0.05^{\mathrm{b}}$ & $12.59 \pm 0.14^{\mathrm{e}}$ & $0.48 \pm 0.16^{\mathrm{b}}$ & $11.74 \pm 0.69^{b}$ & \\
\hline
\end{tabular}

Note: Sites 1, 2, 3, 4 and 5 are the southern, central, northern, western and eastern sites of the Gurbantunggut Desert, respectively. EC, electrical conductivity; SOC, soil organic carbon. Different lowercase letters in the same column indicate significance among study sites at $P<0.05$ level. Mean \pm SE.

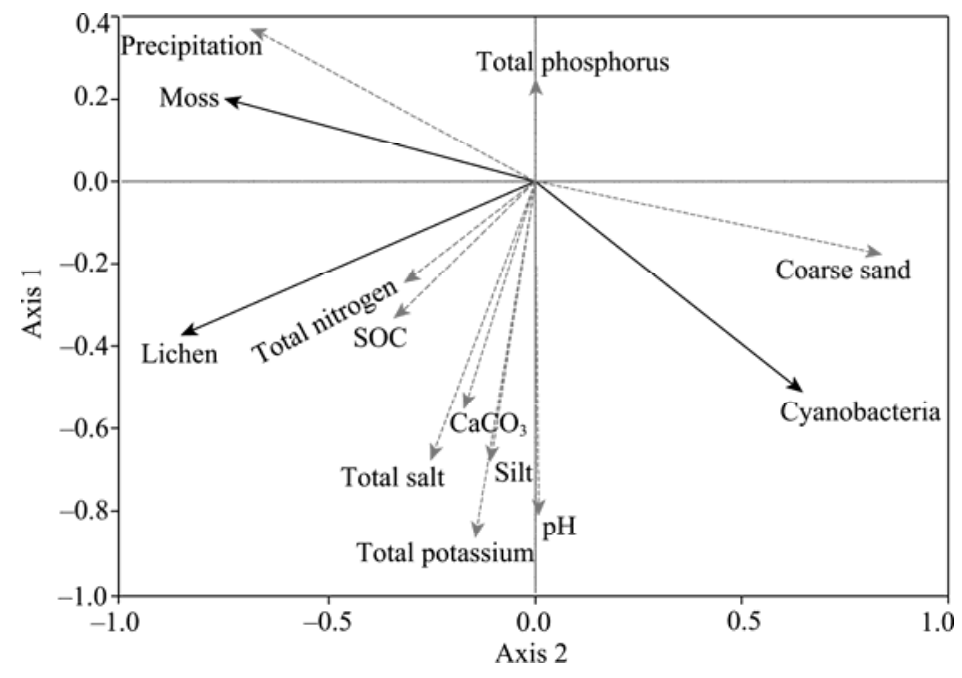

Fig. 2 Redundancy analysis (RDA) bi-plot of BSCs (biological soil crusts) cover and environmental variables at a macro scale. Moss, moss crust cover; Cyanobacteria, cyanobacteria crust cover; Lichen, lichen crust cover; SOC, soil organic carbon.

and Axis 2 was precipitation (canonical coefficients of -0.68 and 0.58 , respectively). The second axis of the RDA explained $13.2 \%$ of the total variation in the cover of BSCs and an additional $18.7 \%$ of the relationship between BSCs cover and environmental variables. The overall ordination explained $87.6 \%$ of the total variation in BSCs cover and $100.0 \%$ of the relationship between BSCs cover and environmental variables. Results shown in Figure 2 demonstrate that moss crust cover was significantly and positively correlated with precipitation, but negatively correlated with coarse sand content. In contrast, cyanobacteria crust cover was positively correlated with coarse sand content. The results suggest that in regions with higher precipitation, cyanobacteria crusts would be replaced by moss and lichen crusts. As the content of coarse sand increased, lichen crust cover decreased. Lichen and cyanobacteria crusts were also slightly affected by soil $\mathrm{pH}$, SOC, soil nitrogen and total salt. Total potassium was shown to be a weak explanatory variable with a canonical coefficient of -0.17 on the first axis.

Results of RDA demonstrate that precipitation and soil particle size (represented by coarse sand content) are the main environmental variables that affect the distribution of BSCs in the Gurbantunggut Desert. Based on the correlation between the distribution of BSCs and the 
dominant environmental variables (precipitation and soil particle size), we constructed a theoretical diagram to intuitively describe the spatial distribution of BSCs along an environmental gradient (Fig. 3). The diagram indicates that the spatial distribution of BSCs is closely related to the variations in soil particle size (represented by coarse sand content) and precipitation. Cyanobacteria-dominated BSCs occurred in areas with the lowest precipitation where the content of coarse sand was highest. Lichen and moss crusts are predominant in the southern site with the highest level of precipitation and the lowest level of coarse sand.

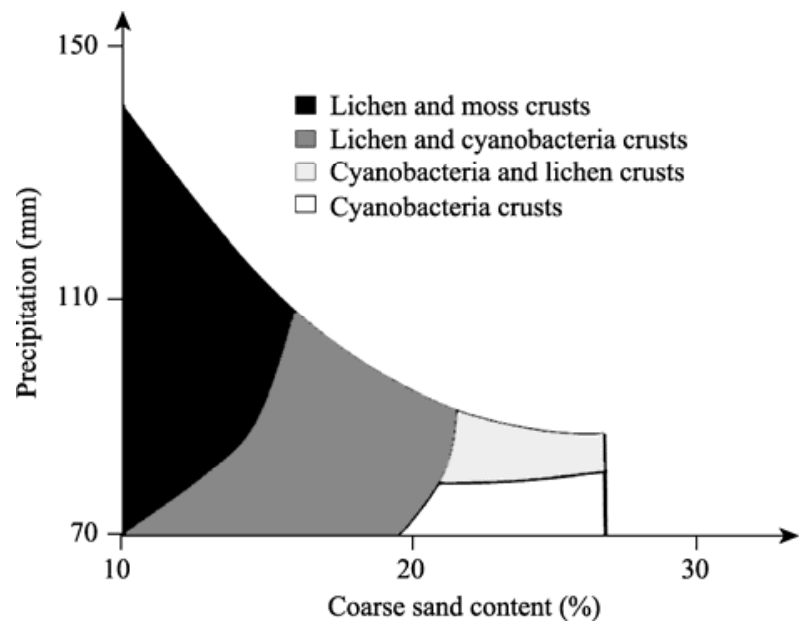

Fig. 3 Theoretical diagram in describing the distribution of BSCs along the precipitation and coarse sand content gradients in the Gurbantunggut Desert

\section{Discussion}

\subsection{Impact of environmental variables on the distribution of BSCs}

The impact of precipitation on the distribution of BSCs has been recognized in arid areas elsewhere in the world (Eldridge and Tozer, 1997; Belnap et al., 2007; Li, 2012). Zhao et al. (2010) suggested that cyanobacteria crusts have higher carbon gains when moisture levels are low, for example in sunny, open habitats; in contrast, moss-dominated BSCs have higher carbon gains in moist conditions that would be found in shaded habitats. Thus, lower levels of precipitation could stimulate the development of cyanobacteria crusts. However, it should be noted that cyanobacteria crusts were gradually replaced by moss and lichen crusts as precipitation increased. In this study, precipitation was positively correlated with the cover of moss and lichen crusts, and negatively correlated with cyanobacteria crust cover. In some areas of the Tengger Desert in Inner Mongolia of China, the cover of moss crusts can even reach up to about $100.00 \%$ (Li et al., 2010); in contrast, in swales (sand dune hollows) of the Gurbantunggut Desert, the cover of moss crusts is less than $18.12 \%$, confirming that the relationship between moss cover and precipitation is much higher in the Tengger Desert than in the Gurbantunggut Desert. Li (2012) suggested that in the Tengger Desert, regions with relatively high precipitation of 200-350 mm are beneficial for the formation of moss crusts. Furthermore, lichen-dominated BSCs are usually found in regions with annual precipitation of 100-200 $\mathrm{mm}$, and cyanobacteria crusts are restricted to regions where the annual precipitation is less than $100 \mathrm{~mm}$. Our study confirmed the results of Li (2012), i.e., lichen-dominated BSCs in the Gurbantunggut Desert are found mainly in the southern region where the mean annual precipitation is more than $130 \mathrm{~mm}$, and cyanobacteria crusts are restricted to regions with a mean annual precipitation of less than $90 \mathrm{~mm}$. However, in the central region of the Gurbantunggut Desert, where the mean annual precipitation is about $80 \mathrm{~mm}$, both lichen and moss crusts can cover up to $65.43 \%$ and $11.75 \%$ of the soil surface, respectively. Soil properties and dew deposition may contribute to their unexpected successful growth in these regions.

The RDA results show that soil particle size is significantly correlated with the cover of BSCs. 
Underlying soils can be modified by the facilitation of dust deposition by BSCs, thus leading to an increase in the silt and clay fraction (Li et al., 2010). However, in the Gurbantunggut Desert, variation in soil particle size is predominantly due to wind activity at the macro level. The proportion of coarse sand is higher and the instability of the soil increases with a corresponding increase in wind speed (Wang et al., 2006). As desert soils in the Negev Desert become finer textured and more stable, the cover of both lichen and moss crusts increases together with an increase in plant species richness (Bowker, 2007; Kidron et al., 2010). In the Tengger Desert, all BSCs are distributed in locations where soil particles are of a grain size in the range of $0.01-0.05$ $\mathrm{mm}$, suggesting that particles of this size, albeit smaller than the particle size recorded for silt in this study, may provide a suitable substrate and serve as a prerequisite to the formation of soil crusts (Duan et al., 2003). In the current study, there was a positive correlation between cyanobacteria crust cover and coarse sand content, and a negative correlation between moss crust cover and coarse sand content and between lichen crust cover and coarse sand content. Cyanobacteria are motile with the ability to move upwards through overlying sediments to reach the light levels needed for photosynthesis, while lichens and mosses are incapable of such movement and often do not survive being covered by soil (Belnap and Gillette, 1998). In this study, few cyanobacteria crusts were found in the eastern site of the Gurbantunggut Desert which harbors the coarsest sand. The central site of the desert is characterized by finer textured sand and limited precipitation, resulting in high lichen crust cover and moss crust cover. The most abundant BSCs developed in the southern site which has the highest precipitation and least coarse sand content (Fig. 3).

In addition to the relationships among the distribution of BSCs, precipitation and soil particle size, this study introduces some potential explanations for heterogeneous growth patterns of BSCs at a macro scale, such as SOC, soil total nitrogen, total potassium, total phosphorus and soil $\mathrm{pH}$. BSCs are carbon- and nitrogen-fixing organisms that strongly influence the chemical characteristics of the underlying soil, so the actual impact of soil properties on the distribution of BSCs could be greater than the current estimate. A positive relationship among cyanobacteria, lichen and soil $\mathrm{pH}$ has been documented in numerous studies (e.g., Bowker et al., 2005; Lalley et al., 2006a; Li et al., 2010). Unexpectedly, soil pH was negatively correlated with moss crust cover in our study (Fig. 2), probably because the impact of soil $\mathrm{pH}$ on BSCs depends on the species composition of BSCs. Soil total phosphorus and potassium can facilitate the growth of vascular plants by increasing shading and limiting access to light, decreasing nutrient availability and increasing litter levels, leading to a net negative impact on the growth of mosses and lichens. In semi-arid areas of eastern Australia and northeastern Ohio, BSCs cover and lichen diversity increase in soils with high $\mathrm{CaCO}_{3}$ content (Grondin and Johansen, 1995; Eldridge and Tozer, 1997). However, in this study, $\mathrm{CaCO}_{3}$ content had little impact on BSCs cover at a macro scale. $\mathrm{CaCO}_{3}$ is known to facilitate colonization by cryptogamic plants in arid lands where $\mathrm{CaCO}_{3}$ content is relatively low. However, only weakly enhanced development of BSCs was recorded in our study sites because the soils already contain relatively high levels of $\mathrm{CaCO}_{3}$.

\subsection{Suggestions on the regeneration and rehabilitation of BSCs}

BSCs play many important ecological roles in arid lands, especially obvious for increasing soil stability (Eldridge, 1998; Eldridge and Leys, 2003) and nutrient availability (Bowker, 2007). Therefore, regeneration and rehabilitation of BSCs are becoming increasingly important for soil stability in desert ecosystems. So far, some research has been successfully conducted on the artificial culture of moss-dominated BSCs in semi-arid regions (Bai et al., 2003; Tian et al., 2005; Rao et al., 2009), and great difficulties in the artificial culture of BSCs were encountered in arid regions. However, in the Gurbantunggut Desert, well-developed BSCs have been observed in straw checkboards that were fixed for 2-5 years. The straw checkerboard can increase the silt and clay content, thereby changing coarse soil texture to fine soil texture ( $\mathrm{Li}$ et al., 2006; Jia et al., 2008). Both lichen and moss crusts were developed well in the central region of the Gurbantunggut Desert (Tables 1 and 2) where mean annual precipitation is about $80 \mathrm{~mm}$. Soil properties and dew deposition may contribute to the unexpected successful growth of lichen and 
moss crusts in these areas. Regeneration and rehabilitation of BSCs can be addressed in part by stabilizing soil and augmenting resource deficiencies such as moisture and nutrients (Bowker, 2007). Therefore, this research further suggests that if soil is relatively stable and moisture levels are appropriate, then the recovery time of BSCs could be hastened. Moreover, the addition of phosphorus and potassium has the potential to promote the growth of BSCs and improve the overall soil properties. The Gurbantunggut Desert has a huge area of $48 \times 10^{3} \mathrm{~km}^{2}$, so large-scale regeneration and rehabilitation programs are not feasible in this way. However, results from this study could be incorporated into small-scale regeneration programs along highways and railways, and on the margins of towns and villages where the addition of fine grained soil particles (silt), moisture and key soil elements including phosphorus and potassium, would be possible.

\section{Conclusions}

The most extensive cover of moss and lichen crusts occurs in the southern site of the Gurbantunggut Desert. BSCs are less abundant in the central site of the desert and least in the eastern and western sites. The lowest levels of precipitation occur in the central and eastern sites, and the highest levels in the southern, western and northern sites. Differences in soil particle size appear to be contingent on prevailing wind directions, showing decreasing trend from the northern site to the southern site, and from both western and eastern sites to the central site of the desert.

Cyanobacteria-dominated BSCs occurred in regions with lower precipitation and higher content of coarse sand. Cyanobacteria and lichen crusts, regardless of whether cyanobacteria or lichenes were dominant, gradually appear in regions with higher precipitation and lower content of coarse sand. Lichen and moss crusts are predominant in the southern site where precipitation level is high and coarse sand content is low.

Precipitation and soil particle size are the major factors limiting the spatial distribution of BSCs at a macro scale. More importantly, the changes in the types of dominant BSCs along environmental gradients indicate that increasing precipitation in arid lands has the potential to facilitate the growth and development of BSCs. Soil $\mathrm{pH}$ and total potassium also explain some of the heterogeneous growth patterns of BSCs at a macro scale. The detailed relationships between environmental variables and development of BSCs need to be further evaluated by controlled experiments in the future research.

\section{Acknowledgements}

This work was supported by the National Natural Science Foundation of China $(41571256,41401296)$. We would like to thank LIU Yaobing, TAO Ye, ZHOU Xiaobing, ZHOU Zhibing and LI Guodong for their help in the field work and lab analyses. We are also grateful to the Fukang National Field Scientific Observation and Research Station for Desert Ecosystems and Xinjiang Petroleum Administrative Bureau for providing meteorological data. Special thanks to ZHANG Jing and SU Yangui for their helpful suggestions on this manuscript.

\section{References}

Bai X L, Wang Y, Xu J, et al. 2003. Characteristics of reproduction and growth of mosses in the soil crust of fixed dunes in Shapotou area. Journal of Desert Research, 23(2): 171-173. (in Chinese)

Belnap J, Gillette D A. 1998. Vulnerability of desert biological soil crusts to wind erosion: the influences of crust development, soil texture, and disturbance. Journal of Arid Environments, 39(2): 133-142.

Belnap J. 2001. Comparative structure of physical and biological soil crusts. In: Belnap J, Lang O L. Biological Soil Crusts: Structure, Function, and Management. Berlin: Springer, 177-191.

Belnap J. 2003. The world at your feet: desert biological soil crusts. Frontiers in Ecology and the Environment, 1(4): 181-189.

Belnap J. 2006. The potential roles of biological soil crusts in dryland hydrologic cycles. Hydrological Processes, 20(15): 3159-3178.

Belnap J, Phillips S L, Smith S D. 2007. Dynamics of cover, UV-protective pigments, and quantum yield in biological soil crust communities of an undisturbed Mojave Desert shrubland. Flora, 202(8): 674-686. 
Bowker M A, Belnap J, Davidson D W, et al. 2005. Evidence for micronutrient limitation of biological soil crusts: importance to arid-lands restoration. Ecological Applications, 15(6): 1941-1951.

Bowker M A, Belnap J, Davidson D W, et al. 2006. Correlates of biological soil crust abundance across a continuum of spatial scales: support for a hierarchical conceptual model. Journal of Applied Ecology, 43(1): 152-163.

Bowker M A. 2007. Biological soil crust rehabilitation in theory and practice: An underexploited opportunity. Restoration Ecology, 15(1): 13-23.

Bu C F, Zhang P, Wang C, et al. 2016. Spatial distribution of biological soil crusts on the slope of the Chinese Loess Plateau based on canonical correspondence analysis. Catena, 137: 373-381.

Büdel B, Darienko T, Deutschewitz K, et al. 2009. Southern African biological soil crusts are ubiquitous and highly diverse in drylands, being restricted by rainfall frequency. Microbial Ecology, 57(2): 229-247.

Castenholz R W, Garcia-Pichel F. 2000. Cyanobacterial responses to UV radiation. In: Whitton B A, Potts M. Ecology of Cyanobacteria: Their Diversity in Time and Space. Dordrecht: Kluwer, 591-611.

Chen Y N, Wang Q, Li W H, et al. 2007. Microbiotic crusts and their interrelations with environmental factors in the Gurbantonggut desert, western China. Journal of Environmental Geography, 52(4): 691-700.

Deines L, Rosentreter R, Eldridge D J, et al. 2007. Germination and seedling establishment of two annual grasses on lichen-dominated biological soil crusts. Plant and Soil, 295(1-2): 23-35.

Duan Z H, Wang G, Xiao H L, et al. 2003. Abiotic soil crust formation on dunes in an extremely arid environment: a 43-year sequential study. Arid Land Research and Management, 17(1): 43-54.

Eldridge D J, Tozer M E. 1997. Environmental factors relating to the distribution of terricolous bryophytes and lichens in semi-arid eastern Australia. Bryologist, 100(1): 28-39.

Eldridge D J. 1998. Trampling of microphytic crusts on calcareous soils, and its impact on erosion under rain-impacted flow. Catena, 33(3-4): 221-239.

Eldridge D J. 2003. Biological soil crusts of Australia. In: Belnap J, Lang O L. Biological Soil Crusts: Structure, Function, and Management. Berlin: Springer, 119-132.

Eldridge D J, Leys J F. 2003. Exploring some relationships between biological soil crusts, soil aggregation and wind erosion. Journal of Arid Environments, 53(4): 457-466.

Garibotti I A, Polo M G, Tabeni S. 2018. Linking biological soil crust attributes to the multifunctionality of vegetated patches and interspaces in a semiarid shrubland. Functional Ecology, 32(4): 1065-1078.

Grondin A E, Johansen J R. 1995. Seasonal succession in a soil algal community associated with a beech-maple forest in northeastern Ohio, USA. Nova Hedwigia, 60(1-2): 1-12.

Jia R L, Li X R, Liu L C, et al. 2008. Responses of biological soil crusts to sand burial in a revegetated area of the Tengger Desert, Northern China. Soil Biology and Biochemistry, 40(11): 2827-2834.

Kidron G J, Barzilay E, Sachs E. 2000. Microclimate control upon sand microbiotic crusts, western Negev Desert, Israel. Geomorphology, 36(1-2): 1-18.

Kidron G J, Vonshak A, Dor I, et al. 2010. Properties and spatial distribution of microbiotic crusts in the Negev Desert, Israel. Catena, 82(2): 92-101.

Kindt R, Coe R. 2005. Tree Diversity Analysis. A Manual and Software for Common Statistical Methods for Ecological and Biodiversity Studies. Nairobi: World Agroforestry Centre (ICRAF).

Lalley J S, Viles H A, Copeman N, et al. 2006a. The influence of multi-scale environmental variables on the distribution of terricolous lichens in a fog desert. Journal of Vegetation Science, 17(6): 831-838.

Lalley J S, Viles H A, Henschel J R, et al. 2006b. Lichen-dominated soil crusts as arthropod habitat in warm deserts. Journal of Arid Environments, 67(4): 579-593.

Li X R, Xiao H L, He M Z, et al. 2006. Sand barriers of straw checkerboards for habitat restoration in extremely arid desert regions. Ecological Engineering, 28(2): 149-157.

Li X R, He M Z, Zerbe S, et al. 2010. Micro-geomorphology determines community structure of biological soil crusts at small scales. Earth Surface Processes and Landforms, 35(8): 932-940.

Li X R, Jia R L, Chen Y W, et al. 2011. Association of ant nests with successional stages of biological soil crusts in the Tengger Desert, Northern China. Applied Soil Ecology, 47(1): 59-66.

Li X R. 2012. Eco-hydrology of Biological Soil Crusts in Desert Regions of China. Beijing: Higher Education Press, 50-59. (in Chinese)

Morse J W, Arvidson R S, Lüttge A. 2007. Calcium carbonate formation and dissolution. Chemical Reviews, 107(2): $342-381$.

Nanjing Institute of Soil Research, Chinese Academy of Sciences. 1980. Analysis of Soil Physico-Chemical Features. Shanghai:

Shanghai Science and Technology Press, 1-260. (in Chinese) 
Peter G, Leder C V, Funk F A. 2016. Effects of biological soil crust and water availability on seedlings of three perennial Patagonian species. Journal of Arid Environments, 125: 122-126.

Pietrasiak N, Johansen J R, Drenovsky R E. 2011. Geologic composition influences distribution of microbiotic crusts in the Mojave and Colorado Deserts at the regional scale. Soil Biology and Biochemistry, 43(5): 967-974.

Pietrasiak N, Regus J U, Johansen J R, et al. 2013. Biological soil crust community types differ in key ecological functions. Soil Biology and Biochemistry, 65: 168-171.

Qian Y B, Wu Z N, Yang H F, et al. 2009. Spatial heterogeneity for grain size distribution of aeolian sand soil on longitudinal dunes in the southern Gurbantunggut Desert. Journal of Arid Land, 1(1): 26-33.

Rao B Q, Liu Y D, Hu C X, et al. 2009. The technology of man-made algal crust and its applications in control of desertification. Acta Hydrobiologica Sinica, 33(4): 756-761. (in Chinese)

Rivera-Aguilar V, Godínez-Alvarez H, Moreno-Torres R, et al. 2009. Soil physico-chemical properties affecting the distribution of biological soil crusts along an environmental transect at Zapotitlán drylands, Mexico. Journal of Arid Environments, 73(11): 1023-1028.

Rogers R W. 2006. Soil surface lichens on a 1500 kilometre climatic gradient in subtropical eastern Australia. Lichenologist, 38(6): 565-576.

ter Braak C F J. 1988. CANOCO-an extension of DECORANA to analyze species-environment relationships. Hydrobiologia, 75(3): $159-160$

Thomas A D, Dougill A J. 2007. Spatial and temporal distribution of cyanobacterial soil crusts in the Kalahari: implications for soil surface properties. Geomorphology, 85(1-2): 17-29.

Tian G Q, Bai X L, Xu J, et al. 2005. Experimental studies on natural regeneration and artificial cultures of moss crusts on fixed dunes in the Tengger Desert. Chinese Journal of Plant Ecology, 29(1): 164-169. (in Chinese)

Wang X Q, Zhang Y M, Wang Y C, et al. 2006. Eco-environment change of biological crusts on longitudinal dune surface in Gurbantunggut Desert. Journal of Desert Research, 26(5): 711-716. (in Chinese)

West N E. 1990. Structure and function of microphytic soil crusts in wildland ecosystems of arid to semi-arid regions. Advances in Ecological Research, 20(1): 179-223.

Williams A J, Buck B J, Soukup D A, et al. 2013. Geomorphic controls on biological soil crust distribution: A conceptual model from the Mojave Desert (USA). Geomorphology, 195: 99-109.

Zhang Y M, Pan H X, Pan B R. 2004. Distribution characteristics of biological soil crust on sand dune surface in Gurbantunggut Desert, Xinjiang. Journal of Soil and Water Conservation, 18(4): 61-64. (in Chinese)

Zhang Y M, Chen J, Wang L, et al. 2007. The spatial distribution patterns of biological soil crusts in the Gurbantunggut Desert, Northern Xinjiang, China. Journal of Arid Environments, 68(4): 599-610.

Zhao Y G, Xu M X, Belnap J. 2010. Response of biocrusts' photosynthesis to environmental factors: a possible explanation of the spatial distribution of biocrusts in the Hilly Loess Plateau region of China. Acta Ecologica Sinica, 30(17): 4668-4675. (in Chinese) 